\title{
The Impact of COVID-19 on the Chinese Stock Market: An Event Study Based on the Consumer Industry
}

\author{
Lei Yan ${ }^{1}$, Yanhong Qian² a \\ ${ }^{1}$ China Academy of Financial Research, Zhejiang University of Finance \& Economics, China., ${ }^{2}$ Zhejiang University of Finance \& Economics, China \\ Keywords: covid-19, stock price, consumer industry \\ $\underline{10.46557 / 001 c .18068}$
}

\section{Asian Economics Letters}

\begin{abstract}
Using an event study approach, this paper investigates the impact of the coronavirus pandemic (COVID-19) on the consumer industry in the Chinese stock market. We find that stocks belonging to the consumer industry was adversely impacted by the pandemic in the first three trading days after the incident. However, this impact is transitory. With the implementation of government policies, stock returns of the industry maintain steady growth.
\end{abstract}

\section{Introduction}

The sudden outbreak of the COVID-19 pandemic at the beginning of 2020 has had a negative impact on the global economy. As an important capital market of a country, the stock market can intuitively reflect residents' financial behavior and a country's economic conditions. Faced with COVID-19, firms have been impacted differently depending on their industry. To be specific, enterprises that are nonstate-owned, engage in foreign trade or have few assets are more vulnerable to pandemics (Chen, 2020). Moreover, the pandemic contains risk transmission and risk spillover to other markets. Fang et al. (2020) analyze the influence of COVID-19 on the risk spillover of the money market, stock market, and other exchange markets based on an event study framework. They find that the COVID-19 pandemic had an immediate effect on various financial markets and the risk spillover of each market increases after 3-5 days of the event.

The literature on the COVID-19 pandemic is evolving (see Phan \& Narayan, 2020; Sha \& Sharma, 2020), and todate studies have paid less attention to the consumer industry. The outbreak of the pandemic by restricting travel and movement of people has disrupted offline consumer purchases. It follows that even the basic consumption demands are difficult to guarantee. In this case, consumer pessimism may be transmitted to the stock market. Yu \& Zhu (2015) find that investor sentiment has a notable negative impact on the stock price co-movement, indicating that the more pessimistic the consumer sentiment, the more intense the stock market's response. On the other hand, Wang (2017) uncovers the inverse impact of Chinese stock price on consumer demand.

Employing an event-study approach, this paper examines the effect of the COVID-19 pandemic on the stock price movements of the consumer industry in China. The empirical results show that the COVID-19 pandemic had a huge impact on China's consumer stock market in the short term. However, as the event unfolded, the return on consumer stocks gradually recovered. This finding implies that the impact of the pandemic on stocks of the consumer industry is limited and can be viewed as a conditional short-term phenomenon.

\section{Methodology and Data}

\section{A. Methodology}

The event study allows one to evaluate abnormal changes in sample stock prices (or index) following a specific event. Kothari \& Warner (2007) provide an overview of the event study methods and conclude that short-horizon methods are quite reliable. Therefore, in this paper, we use an event study approach to examine the relationship between the COVID-19 pandemic and the abnormal returns in China's stock market.

There are three models to estimate the normal rate of return, that is, the constant mean returns model, the market model, and the market adjustment model; see Kaketsis \& Sarantis (2006). We find that intervention changes are assumed to be associated with the response of market rates in both the market model and the market adjustment model. Considering that the market rate of return is always changing and cannot be accurately determined by a fixed value, we use the constant mean return model to estimate the normal return rate, which is outlined as follows:

$$
\begin{aligned}
R_{i v} & =\mu_{i}+\eta_{i v} \\
\sigma_{\eta_{i v}} & =\frac{1}{V-1} \sum_{v=1}^{v}\left(R_{i v}-\mu_{i}\right)^{2}
\end{aligned}
$$

Using the average index return, we can calculate the abnormal return $\left(A R_{i t}\right)$ :

$$
A R_{i t}=R_{i v}-\mu_{i}
$$

Then, we calculate the cumulative abnormal rate of return $C A R_{j}$ for an event window $\left(T_{1}, T_{2}\right)$ is computed as:

$$
C A R_{j, T_{1}, T_{2}}=\sum_{t=T_{1}}^{T} A R_{j t}
$$

where, $R_{i v}$ is the market return rate of the trading market, $\mu_{i}$ is the actual market return rate; $\sigma_{\eta}$ is the variance of the sample in the estimation window, $V$ is the length of the es-

\footnotetext{
a Corresponding author: China Academy of Financial Research, Zhejiang University of Finance \& Economics. No.18, Xueyuan Street, Xiasha Higher Education Zone, Hangzhou Zhejiang 310018, P.R. China Email: yhqian@zufe.edu.cn.
} 
Table 1. The impact of COVID-19 within different event windows

\begin{tabular}{llccc}
\hline Event window & CAR & SCAR & $p$-value & sig \\
\hline$[-2,2]$ & -0.1063 & -9.9680 & 0 & $* * *$ \\
{$[-5,5]$} & -0.0228 & -2.1350 & 0.0345 & $* *$ \\
{$[-10,10]$} & -0.0042 & -0.3907 & 0.6966 & $*$ ** \\
{$[-15,15]$} & 0.0369 & 3.4643 & 0.0007 & 0.1379 \\
{$[-30,30]$} & 0.0159 & 1.4922 & \\
\hline
\end{tabular}

This table reports the regression results. Column 1 notes the event windows, column 2 has the CAR results, column 3 has the standardized cumulative abnormal return(SCAR) results, the p-value testing the null hypothesis is zero appears in the second last column while the last column has statistical significance note where* $\mathrm{p}<0.1$, *** $\mathrm{p}<0.05$, and $* * * * 0.01$.

timation window and $v$ is any time in the event window. In this paper, and $\mu_{i}$ is the average index return rate over 140 trading days in the estimation window.

Based on the constant mean model, this paper examines the stock market's reaction to the event in the event window and uses $t$ tests to assess whether the outbreak of the event had implications for abnormal returns.

\section{B. Data}

On January 22, 2020 infected patients were identified and reported in 24 provinces of China. Meanwhile, the State Council Information Office held the first official conference on the pandemic on that day, which could be regarded as a signal that the pandemic in China had officially entered an outbreak state. Therefore, we choose January 22, 2020 as the event day of the COVID-19 outbreak. To improve the accuracy of the estimation as much as possible, we choose 140 trading days before the event date as the forecast period following Pan \& Shi (2012). In order to capture the impact of major events on market expectations, it is necessary to examine event windows with different lengths. Therefore, this paper sets the event window for the outbreak of the pandemic as $[-2,2],[-5,5],[-10,10],[-15,15]$ and $[-30,30]$.

The Shanghai Stock Exchange (SSE) Consumer 80 Index is used to measure the performance of stocks of the consumer industry. This index consists of 80 major consumers, optional consumer and medical \& health companies in the Shanghai A-shares. The data are obtained from the RESSET Financial Database (http://www.resset.cn/), which provides professional services for model testing, investment research, among others.

\section{Empirical results}

From Figure 1, we see the time trends of abnormal returns in consumer stocks. On the day that COVID-19 set in, the abnormal rate was unaffected. However, after the Spring Festival, the consumer stock experienced severe turbulence, which saw the abnormal return drop by $7 \%$. In addition, although the abnormal rate had risen in the next few days, it is obvious that the stock market after the pandemic remained volatile, and the fluctuations were severe than before.

Figure 2 reports the time trends of the cumulative abnormal returns during the event windows. After the event day, we can see a sharp decline from $5 \%$ to $-4 \%$. Yet, on day 4 , the CAR of the consumer industry started to rebound; it returned to positive values on the sixth event day and was in the $1 \%$ and $7 \%$ range from thereafter. This means that shocks like COVID-19 may produce a huge impact on the

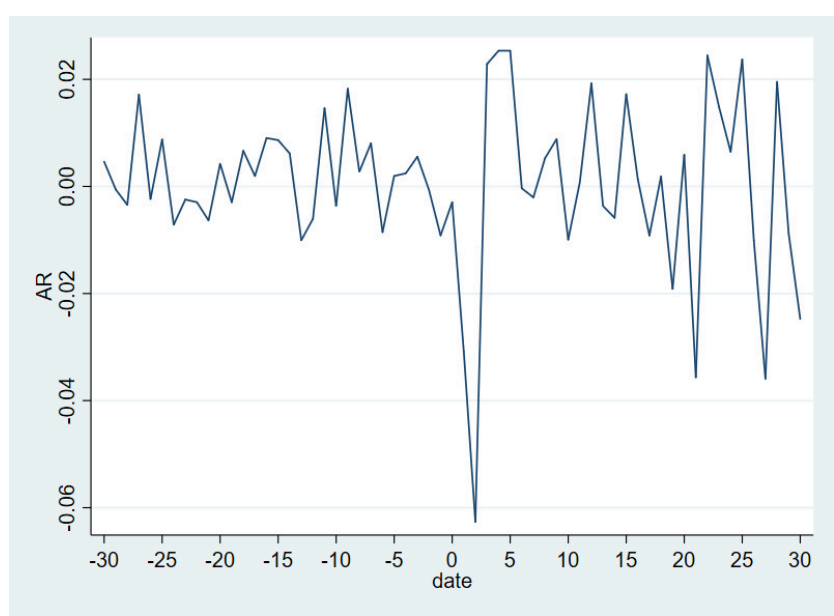

Figure 1. Time trends of abnormal returns in customer stock

This figure reports the abnormal returns 30 days before and 30 days after the event.

stock market within a short period of time, but as time passes and the event unfolds, its influence will gradually weaken.

The same conclusions can be obtained from the regression analysis. As shown in Table 1, the impact of COVID-19 is negative and statistically significant in the event windows of $[-2,2]$ and $[-5,5]$ at the $1 \%$ and $5 \%$ level, respectively. As the windows expanded, the negative impact of COVID-19 on the consumer industry falls in both significance level and magnitude. In the windows of $[-10,10]$, the effects of COVID-19 are not statistically significant. When the event window is expanded to $[-15,15]$, the impact of COVID-19 turns out to be positive at the $1 \%$ level of significance. However, this positive impact is transitory as we can observe that the significance disappears in the window of $[-30,30]$.

Some reasons may explain this phenomenon. As the stock prices fell, the Chinese government introduced a series of monetary policies to regulate the economy, which effectively helped to stabilize the stock market. In addition, the outbreak of the pandemic has positively influenced some industries, such as medical service, health, and information technology (He et al., 2020). Moreover, online shopping platforms and the mature logistics system in China also played an important role in boosting consumption during the pandemic. 


\section{Conclusion}

In this paper, we study the short-term impacts of the COVID-19 pandemic on stocks of the consumer industry in China. We employ an event study approach and use the Shanghai Stock Exchange 80 Index as the data sample. The empirical results show that the onset of COVID-19 had a significantly negative impact on consumer stocks at the very beginning of the crisis, especially on the second day after the crisis occurred. However, its negative impact does not last long. The consumer industry recovered quickly due to the government's effective monetary policies and the well-developed online shopping industry in China.

Submitted: October 30, 2020 AEDT, Accepted: November 19, 2020 AEDT

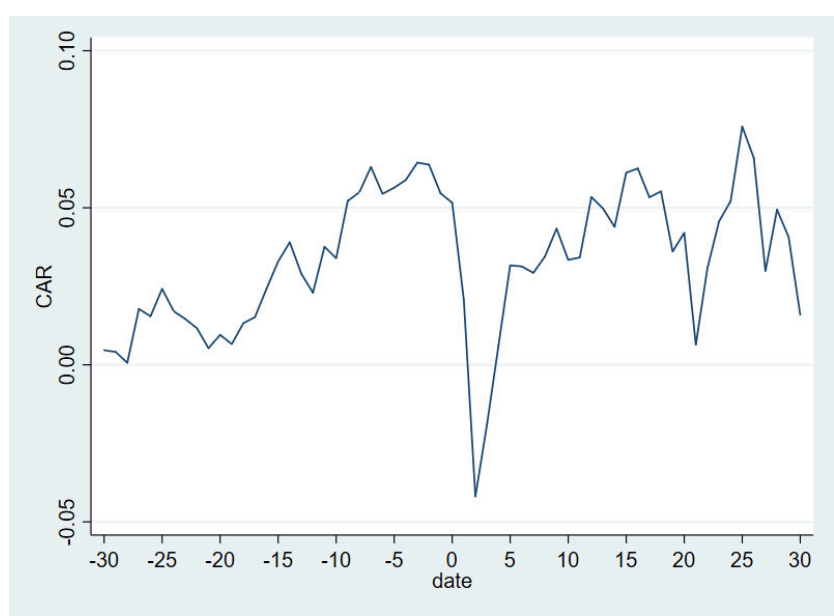

Figure 2. Time trends of Cumulative abnormal returns in customer stock

This figure reports the cumulative abnormal returns 30 days before and 30 days after the event.

This is an open-access article distributed under the terms of the Creative Commons Attribution 4.0 International License (CCBY-SA-4.0). View this license's legal deed at https://creativecommons.org/licenses/by-sa/4.0 and legal code at https://creativecommons.org/licenses/by-sa/4.0/legalcode for more information. 


\section{REFERENCES}

Chen, F. G. (2020). The heterogeneous impact of COVID -19 on Chinese enterprises - Empirical research based on the perspective of stock price fluctuations. Journal of Industrial Technological Economics, 39(10), 3-14. DOI: 10.3969 /j.issn.100 4-910X.2020.10.001

Fang, Y., Yu, B., \& Wang, W. (2020). China's financial market risk measurement and controlling under COVID-19 shock.Journal of. Central University of Finance \& Economics ,2020(08):116-128.DOI:10.19681/ j.cnki.jcufe.2020.08.010. https://doi.org/10.19681/j.cn ki.jcufe.2020.08.010

He, P. L., Sun, L. Y., Zhang, Y., \& Li, T. (2020). COVID-19's impact on stock prices across different sectors-An event study based on the Chinese stock market. Emerging Markets Finance and Trade, 56(10), 2198-2212. https://doi.org/10.1080/1540496X.2020.1 $\underline{785865}$

Kaketsis, A., \& Sarantis, N. (2006). The effects of monetary policy changes on market interest rates in Greece: An event study approach. International Review of Economics \& Finance, 15(4), 487-504. http s://doi.org/10.1016/j.iref.2004.09.003

Kothari, S. P., \& Warner, J. B. (2007). Econometrics of Event Studies. In Handbook of Empirical Corporate Finance (pp. 3-36). https://doi.org/10.1016/b978-0-4 $\underline{44-53265-7.50015-9}$
Pan, H. F., \& Shi, Z. C. (2012). Oil Markets’ Short Run Reactions to Significant Demand Shocks-An Event Study Perspective. Shanghai Journal of Economics, 12, 32-43. https://doi.org/10.19626/j.cnki.cn31-1163/ f.2012.12.004

Phan, D. H. B., \& Narayan, P. K. (2020). Country responses and the reaction of the stock market to COVID-19-A preliminary exposition. Emerging Markets Finance and Trade, 56(10), 2138-2150. http s://doi.org/10.1080/1540496x.2020.1784719

Sha, Y., \& Sharma, S. S. (2020). Research on Pandemics Special Issue of the Journal Emerging Markets Finance and Trade. 56(10), 2133-2137. http s://doi.org/10.1080/1540496x.2020.1795467

Wang, J. S. (2017). A comparative empirical study on the impact of stock price between China and America on consumption demand. Journal of Hangzhou Normal University (Humanities and Social Sciences), 03, 128-136. https://doi.org/10.3969/j.ssn.1674

Yu, Q. L., \& Zhu, H. Q. (2015). Investor sentiment and stock price co-movement -A panel data analysis of China's A-share market. Financial Theory \& Practice, 2015(04), 81-87. 